\title{
Soft X-ray spectroscopy of transition metal compounds: a theoretical perspective
}

\author{
S.I. Bokarev ${ }^{1, *}$, R. Hilal ${ }^{2}$, S.G. Aziz ${ }^{2}$, and O. Kühn ${ }^{1}$ \\ ${ }^{1}$ Institute of Physics, University of Rostock, 8059 Rostock, Germany \\ ${ }^{2}$ Chemistry Department, Faculty of Science, 21589 Jeddah, Saudi Arabia
}

\begin{abstract}
To date, X-ray spectroscopy has become a routine tool that can reveal highly local and element-specific information on the electronic structure of atoms in complex environments. Here, we report on the development of an efficient and versatile theoretical methodology for the treatment of soft X-ray spectra of transition metal compounds based on the multi-configurational self-consistent field electronic structure theory. A special focus is put on the L-edge photon-in/photon-out and photonin/electron-out processes, i.e. X-ray absorption, resonant inelastic scattering, partial fluorescence yield, and photoelectron spectroscopy, all treated on the same theoretical footing. The investigated systems range from small prototypical coordination compounds and catalysts to aggregates of biomolecules.
\end{abstract}

Tracing atomic and molecular levels in the course of various physical and chemical processes, X-ray spectroscopy is one of the most powerful tools to access structure and properties of matter in different states of aggregation. X-ray spectroscopic techniques probe the local electronic structure of a particular atom in its environment. This is in contrast to UV/vis spectroscopy, where transitions generally occur between delocalized molecular orbitals. The combination of different absorption, emission (scattering) as well as photo- and autoionization X-ray methods allows addressing various aspects of ultrafast dynamics and identification of short-lived intermediates of catalytic reactions. However, interpretation of complex experimental spectra and verification of experimental hypotheses is a non-trivial task and a powerful first principles theoretical approach that allows for a systematic investigation of a broad class of compounds is needed. An additional complexity stems from strong electron correlation and spin-orbit coupling in the core-excited electronic states.

We aim at the development of an efficient and versatile theoretical methodology for the treatment of soft X-ray spectra of transition metal compounds based on the multiconfigurational self-consistent field electronic structure theory combined with a perturbative LS-coupling scheme for spin-orbit coupling [1]. A special focus is put on the L-edge photonin/photon-out and photon-in/electron-out processes, i.e. X-ray absorption, resonant inelastic scattering, partial fluorescence yield, and photoelectron spectroscopy treated on the same theoretical footing [2,3]. We address the application of the X-ray metal L-edge and ligand Kedge spectroscopy to unraveling electronic structure, nature of chemical bonds, oxidation,

\footnotetext{
* Corresponding author: sergey.bokarev@uni-rostock.de
} 
and spin-states, the interplay of radiative and non-radiative decay channels in transition metal complexes. The investigated systems range from the small prototypical coordination compounds [4-6] and catalysts [7] to the aggregates of biomolecules [8].

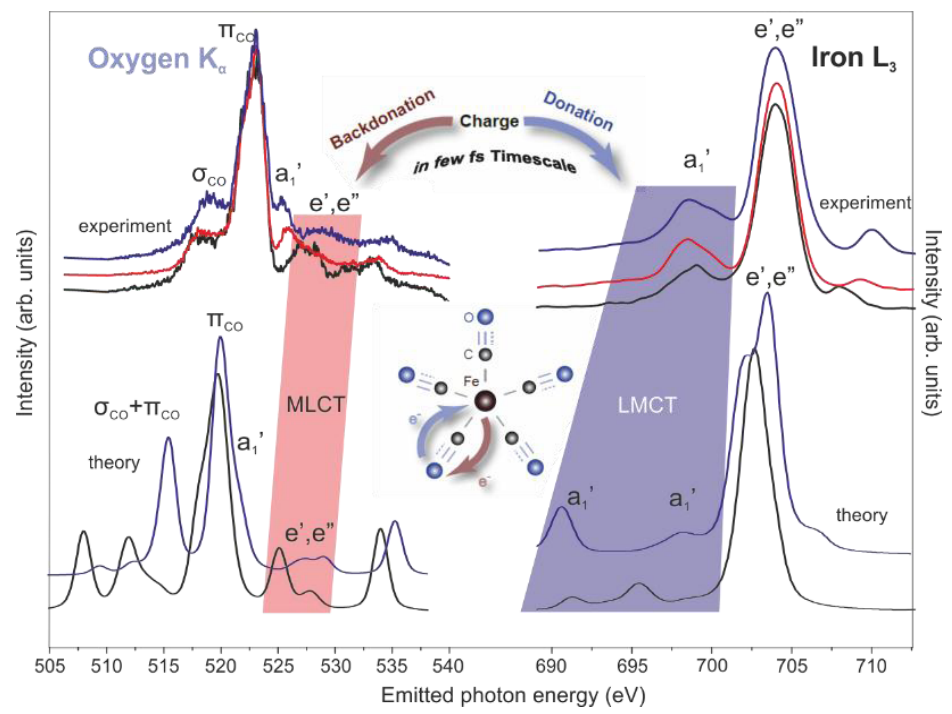

Fig. 1. Experimental and theoretical resonant inelastic X-ray scattering spectra of $\mathrm{Fe}(\mathrm{CO})_{5}$ in solution [4]: Fe L3-edge (right) and O K-edge (left). The charge-transfer peaks (shaded) provide information on the strength of covalent metal-ligand chemical bonds in terms of donation / backdonation mechanism.

The work is conducted in close collaboration with the experimental group of E.F. Aziz (HZB, Berlin). We acknowledge financial support by the Deanship of Scientific Research (DSR), King Abdulaziz University, Jeddah, (grant No. D-003-435).

\section{References}

1. S.I. Bokarev, M. Dantz, E. Suljoti, O. Kühn, E.F. Aziz, Phys. Rev. Lett., 111, 083002 (2013)

2. G. Grell, S.I. Bokarev, B. Winter, R. Seidel, E.F. Aziz, S.G. Aziz, O. Kühn, J. Chem. Phys. 143, 074104 (2015)

3. R. Golnak, S.I. Bokarev, R. Seidel, J. Xiao, G. Grell, K. Atak, I. Unger, S. Thürmer, S.G. Aziz, O. Kühn, B. Winter, E.F. Aziz, Sci. Rep. 6, 24659 (2016)

4. E. Suljoti, R. Garcia-Diez, S.I. Bokarev, K.M. Lange, R. Schoch, B. Dierker, M. Dantz, K. Yamamoto, N. Engel, K. Atak, O. Kühn, M. Bauer, J.-E. Rubensson, E.F. Aziz, Angew. Chem. Int. Ed. 52, 9841 (2013)

5. N. Engel, S.I. Bokarev, E. Suljoti, R. Garcia-Diez, K.M. Lange, K. Atak, R. Golnak, A. Kothe, M. Dantz, O. Kühn, E.F. Aziz, J. Phys. Chem. B 118, 1555 (2014)

6. K. Atak, S.I. Bokarev, M. Gotz, R. Golnak, K.M. Lange, N. Engel, M. Dantz, E. Suljoti, O. Kühn, E.F. Aziz J. Phys. Chem. B 117, 12613 (2013)

7. S.I. Bokarev, M. Khan, M.K. Abdel-Latif, J. Xiao, R. Hilal, S.G. Aziz, E.F. Aziz, O. Kühn, J. Phys. Chem. C 119, 19192 (2015)

8. M. Preuße, S.I. Bokarev, S.G. Aziz, O. Kühn, Struct. Dynamics 3, 062601 (2016) 